\section{Insulin resistance and mechanical dysfunction in hearts of Wistar rats with streptozotocin-induced non-insulin-dependent diabetes mellitus}

Dear Sir,

Schaffer and Wilson [1] report insulin deficiency together with a significant reduction in glucose utilisation and cardiac work in hearts from 14-month-old diabetic rats. It is important to establish whether these diabetic rats had an elevated plasma non-esterified fatty acid (NEFA) concentration as a result of insulin deficiency. In a previous study [2], we found that non-ketonuric diabetes mellitus in the rat results in the elevation of the plasma NEFA concentration (controls: $0.39 \mathrm{mmol} / \mathrm{l}: 0.31-0.80$; 2 -month-old diabetic rats $0.97 \mathrm{mmol} / \mathrm{l}: 0.66-$ $2.05 ; p<0.05)$.

If plasma NEFA concentrations were indeed raised, did cardiac utilisation of this energy source increase concomitantly with the decreased glucose utilisation? This question is relevant since in experimental infarction NEFA have been shown to increase infarct size, reduce myocardial contractility and increase oxygen requirements.

Diabetic ketoacidosis represents a more severe form of diabetes where in conjunction with hyperglycaemia the plasma NEFA concentrations reach very high levels (controls: $0.55 \mathrm{mmol} / \mathrm{l}: 0.42$ 0.64 ; ketoacidotic rats: $2.17 \mathrm{mmol} / \mathrm{l}: 1.88-2.44 ; p<0.001$ ); in this situation, several metabolic variables are disturbed [2]. These changes do not appear to be related to hyperglycaemia, but rather to the uncontrolled lipolysis. In this context, we have previously shown that the oral antilipolytic agent (GR 79236; Glaxo Group Research, ware, Hertfordshire, UK) corrects many of the metabolic variables affected by ketoacidosis, but did not reduce the plasma glucose concentration in this model. For example, the elevated plasma creatine kinase activity of ketoacidotic rats was significantly reduced following GR 79236 treatment [4]. Schaffer and Wilson [1] also conclude that the cardiac dysfunction they observed, correlates with the insulin secretory defect rather than with hyperglycaemia. Furthermore, others [5] found no correlation between hyperglycaemia and decreased creatine kinase content of diabetic rat hearts.

These studies indicate that variables other than hyperglycaemia must be considered when investigating complications associated with long-term diabetes.

Yours sincerely,

\section{References}

1. Schaffer SW, Wilson GL (1993) Insulin resistance and mechanical dysfunction in hearts of Wistar rats with streptozotocin-induced non-insulin-dependent diabetes mellitus. Diabetologia 36: 195199

2. Thompson CS, Mikhailidis DP (1992) Haematological profile and plasma and urinary biochemistry in experimental models of diabetes mellitus-predictive power for human studies. J Pharm Med 2: 241-257

3. Jay RH, Betteridge DJ (1991) The heart and macrovascular disease in diabetes mellitus. In: Pickup J, Williams G (eds) Textbook of diabetes 1st edn. Blackwell Scientific Publications, Oxford, pp 701-718

4. Thompson CS, Mikhailidis DP (1993) Partial correction of impaired creatine kinase activity in diabetic rat heart by physical training. Metabolism 42: 532-533

5. Mokhtar N, Rousseau-Migneron S, Tancrede G et al. (1992) Partial correction of impaired creatine kinase activity in diabetic rat heart by physical training. Metabolism 41: 1004-1008

Dr.D.P. Mikhailidis

Department of Chemical Pathology and Human Metabolism

Royal Free Hospital (University of London)

London NW 32QG

UK

\section{Response from the authors}

Dear Sir,

According to the classic studies of Randle [1], the major bottleneck limiting step in glucose metabolism in the insulin-dependent diabetic heart is inhibition of the glycolytic enzyme, phosphofructokinase. This effect is related to the increased availability and oxidation of fatty acids by the heart. One of the consequences of enhanced $\beta$ oxidation is an accumulation of citrate, a potent inhibitor of phosphofructokinase activity and glucose metabolism.

In contrast to the insulin-dependent diabetic heart, glucose utilization by hearts obtained from the neonatal rat model of non-insulin-dependent diabetes appears to be minimally affected by fatty acid metabolism [2]. Neither tissue long chain fatty acyl CoA nor long chain fatty acylcarnitine levels are affected by the non-insulindependent diabetic condition. Moreover, estimates of $\beta$ oxidation calculated from oxygen consumption data suggest that the decrease in oxygen utilization in the non-insulin-dependent diabetic heart is not caused by an elevation in fatty acid metabolism. Rather, impair- 


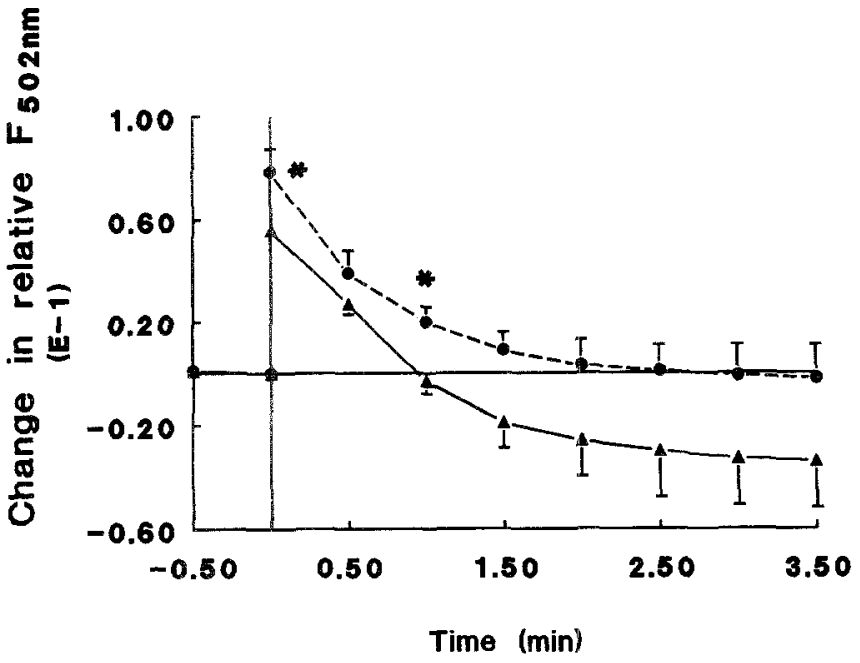

Fig. 1. Effect of non-insulin-dependent diabetes on caffeine-induced $\mathrm{Ca}^{2++}$ release from the sarcoplasmic reticulum of adult cardiomyocytes. Cardiomyocytes were prepared and then loaded with fura 2 using the method described by Allo et al. [3]. Caffeine $(10 \mathrm{mmol} / \mathrm{l})$ was added at time 0 and changes in fluorescence measured over time for cells from control ( $\Delta$ ) and non-insulin-dependent diabetic ( ) hearts. The data are expressed as the difference in relative fluorescence (F) at $502 \mathrm{~nm}$ between cells exposed to caffeine and those incubated in the standard buffer used by Allo et al. [3]. Each point represents the mean \pm SEM of experiments carried out on three different cell preparations. $* p<0.05$ vs nondiabetic control cells

ment in glucose utilization is largely linked to a defect in glucose transport [2].

We agree with the statement by Thompson and Mikhailidis that variables other than hyperglycaemia must be considered when investigating complications of diabetes. We have previously reported that one of the major defects of the non-insulivn-dependent diabetic heart is an impairment in $\mathrm{Na}^{+}, \mathrm{Ca}^{2+}$ exchange, which contributes to an elevation in cytoplasmic calcium levels [3]. Moreover, recent studies with isolated myocytes displayed in Figure 1 show that calcium released from sarcoplasmic reticular stores by $10 \mathrm{mmol} / \mathrm{l}$ caffeine is elevated in non-insulin-dependent diabetes, demonstrating that cytoplasmic calcium levels, as well as intracellular calcium stores, are significantly elevated in the non-insulin-dependent diabetic heart. We believe that this elevation in intracellular calcium causes a reduction in diastolic compliance, triggering abnormalities in ventricular filling and cardiac performance [4].

Yours sincerely;

S. Allo, M. Mozaffari, G. Wilson and S. W. Schaffer

\section{References}

1. Randle PJ, Garland PB, Hales CN, Newsholme EA, Denton RM, Pogson CI (1966) Interactions of metabolism and the physiological role of insulin. Rec Prog Hormone Res 22: 1-44

2. Schaffer SW, Seyed-Mozaffari M, Cutcliff CR, Wilson GL (1986) Postreceptor myocardial metabolic defect in a rat model of noninsulin-dependent diabetes mellitus. Diabetes 35:593-597

3. Allo SN, Lincoln TM, Wilson GL, Green FJ, Watanabe AM, Schaffer SW (1991) Non-insulin-dependent diabetes-induced defects in cardiac cellular calcium regulation. Am J Physiol 260: C1165-C1171

4. Schaffer SW, Mozaffari MS, Artman MF, Wilson GL (1989) Basis for myocardial mechanical defects associated with non-insulin-dependent diabetes. Am J Physiol 256: E25-E30
Dr. S. Schaffer

Department of Pharmacology

College of Medicine

University of South Alabama

MSB 3130

Mobile, AL 36688-0002

USA

\section{Plasma lipoprotein (a) concentration in diabetes mellitus}

Dear Sir,

In a recent article, Császár and co-workers [1] reported no differences in lipoprotein (a) concentration in Type 1 (insulin-dependent) and Type 2 (non-insulin-dependent) diabetic patients when compared to two Caucasian populations (Austrians and Hungarians). They concluded that the $L p(a)$ was not a risk factor contributing to atherosclerotic complications in diabetes.

We have studied a diabetic population and obtained different results some of which do not agree with their conclusions. Forty-four patients diagnosed with Type 2 diabetes, based on the National Diabetes Data Group criteria [2], of less than 5 years duration not taking any lipid lowering drugs, the only treatment being diet modification, were included. None had received insulin or sulphonylureas for at least 1 year before the study. The patients did not have nephrotic syndrome and their proteinuria was lower than $300 \mathrm{mg} /$ day. Plasma cholesterol, HDL cholesterol and plasma triglycerides, were measured by enzymatic methods [3]. LDL cholesterol was calculated using the Friedewald's formula [4]. Lipoprotein A-I and B were quantified in total serum by nephelometry with Behring Institute reagents. $\mathrm{Lp}$ (a) was measured by an enzymeimmunoassay with a monoclonal antibody against $\mathrm{Lp}$ (a) and a polyclonal anti-Lp(a) antibody conjugated with peroxidase. The intra-assay coefficient of variation was $3.1 \%$ and the inter-assay coefficient of variation was $10 \%$. $\mathrm{HbA}_{1 \mathrm{c}}$ was measured by a microcolumn chromatographic method with a reference range between $5.1-7.2 \%$

We found higher $\mathrm{Lp}(\mathrm{a})$ levels in diabetic females (12.40 $\pm 11.34 \mathrm{mg} / 100 \mathrm{ml})$ compared to diabetic males $(5.35 \pm 7.6 \mathrm{mg}$ $100 \mathrm{ml} ; p<0.02)$ and control females $(7.78 \pm 10.10 \mathrm{mg} / 100 \mathrm{ml}$; $p<0.05$ ) (Table 1). We agree with Császár et al. [1] that Lp(a) levels are independent of metabolic control; we do not find differences related to $\mathrm{HbA}_{1 \mathrm{c}}$ when diabetic patients are compared to control subjects as proposed by other authors [5]. The remaining lipid parameters showed a similar pattern as those presented by Czászár et al. The higher $L p(a)$ levels observed in female diabetic patients can be interpreted as an associated factor which could help to explain the increased cardiovascular risk observed in these patients [6].

We believe that risk factors for cardiovascular disease related to higher $L p(a)$ levels in diabetic patients, cannot be extrapolated to the general population. Because conflicting data about this lipoprotein are continuously emerging in the literature they should be interpreted with caution.

Yours sincerely,

J. Vendrell, C. Gutiérrez, R. Pastor, and C. Richart

Acknowledgement. This work was supported by a grant of the PLANICID, number SAL-90-0426.

\section{References}

1. Császár A, Dieplinger H, Sandholzer C et al. (1993) Plasma lipoprotein (a) concentration and phenotypes in diabetes mellitus. Diabetologia 36: 47-51

2. National Diabetes Data Group (1979) Classification diagnosis of diabetes mellitus and other categories of glucose intolerance. Diabetes 28: 1039-1057 